\title{
Meningomielitis asociadas a infección por herpes virus humano 7 . Comunicación de dos casos
}

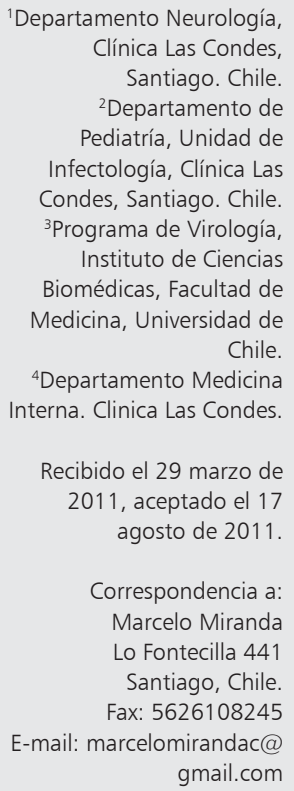

\author{
MARCELO MIRANDA C. ${ }^{1}$, JUAN PABLO TORRES T. ${ }^{2}$, \\ CARMEN LARRAÑAGA L. ${ }^{3}$, GUILLERMO ACUÑA L. ${ }^{4}$
}

\section{Meningomyelitis associated with infection by human herpes virus 7. Report of two cases}

Human herpesvirus 7 (HHV-7) may cause encephalomyelitis in immunocompetent adults. We report two patients infected by the virus. A 34-year-old male presenting with paraparesis and a sensitive deficiency located in D6 dermatome. Cerebrospinal fluid had 35 white blood cells per $\mathrm{mm}^{3}$ and $75 \mathrm{mg}$ protein per dl. A PCR-microarray examination was positive for HHV-7. The patient was treated with prednisolone and ganciclovir with full recovery. A 27-year-old male presenting with headache, fever and diarrhea. Cerebrospinal fluid analysis showed 160 cells per $\mathrm{mm}^{3}$ and $75 \mathrm{mg}$ protein per $\mathrm{dl}$. Viral RNA detection was positive for HHV-7. The patient was managed with analgesia and rest and was discharged with the diagnosis of viral meningitis. Our comunication supports the notion that HHV-7 may be considered as pathogen factor in humans, even in immunocompetent ones.

(Rev Med Chile 2011; 139: 1588-1591).

Key words: Encephalomyelitis; Herpesvirus 7, human; Meningitis, viral.
L

os virus de la familia Herpesviridae como varicela zoster (VVZ), herpes simplex $1 \mathrm{y}$ 2 (VHS-1 y VHS-2) y el citomegalovirus $(\mathrm{CMV})$, son virus neurotrópicos que pueden afectar al sistema nervioso central (SNC). Los virus herpes humano 6 y citomegalovirus pueden ser patógenos, especialmente en pacientes inmunocomprometidos. Las manifestaciones más comunes de los herpes virus incluyen encefalitis, queratitis y trastornos de nervios periféricos (VHS-1); meningoencefalitis en neonatos y meningitis en adultos (VHS-2). La reactivación del VVZ, produce herpes zoster y complicaciones del SNC como mielitis, encefalitis, neuropatia craneal y vascultis focales ${ }^{1}$.

Desde hace menos de 9 años, ha llamado la atención el rol patógeno del virus herpes humano 7 (VHH-7) inicialmente en población pediátrica causando cuadros de convulsiones febriles, epilepsia y encefalitis y en un individuo adulto inmunocompetente una encefalomielitis ${ }^{2,3}$. Posteriormente se ha descrito por Ginanneschi y cols. un paciente inmunocompetente con mielitis y con infección concomitante por citomegalovirus ${ }^{4}$. En nuestro conocimiento, no existen en la literatura más de 3 casos comunicados y ninguno en hispanoamérica de compromiso del SNC por VHH-7. Presentamos 2 pacientes adultos inmunocompetentes con manifestaciones neurológicas asociadas a la detección de VHH-7 en líquido cefalorraquídeo (LCR), mediante técnicas de diagnóstico molecular.

\section{Caso 1}

Un hombre de 34 años de edad, ingeniero, previamente sano, presentó en el curso de 24 horas, fiebre, retención urinaria, debilidad de las extremidades inferiores y déficits sensoriales irregulares en el tórax y abdomen. Como único antecedente, comunicó una tos leve los últimos 4-5 días antes de admisión a la clínica. Una evaluación urológica descartó uropatía obstructiva. $\mathrm{Al}$ examen neu- 
rológico estaba alerta, febril $\left(38^{\circ} \mathrm{C}\right)$, sin déficits en nervios craneales. La fuerza en los miembros superiores era normal, pero se observó una debilidad moderada en las extremidades inferiores con incapacidad para levantarse desde una posición sentada. Los reflejos plantares eran extensores, había déficit sensorial en la parte posterior del cuello y a nivel del dermatoma D6. Los exámenes de rutina: hemograma, velocidad de sedimentación, proteína $\mathrm{C}$ reactiva, hemocultivos y urocultivos fueron negativos $\mathrm{El}$ análisis del LCR mostró 35 glóbulos blancos por $\mathrm{mm}^{3}$, con predominio de células mononucleares. La proteínorraquia fue $75 \mathrm{mg} / \mathrm{dl}$. No se detectaron bandas oligoclonales. La detección de ARN viral por técnica de PCRMicroarray (Entherpex ${ }^{\circledR}$, Genomica, España), fue positiva en el LCR sólo para VHH-7. Los herpes virus VHS-1, VHS-2, VHH-6, Epstein-Barr, VVZ, citomegalovirus y también anterovirus fueron negativos. El test para VIH y HTLV-1 fue negativo, así como pruebas inmunológicas para vasculitis

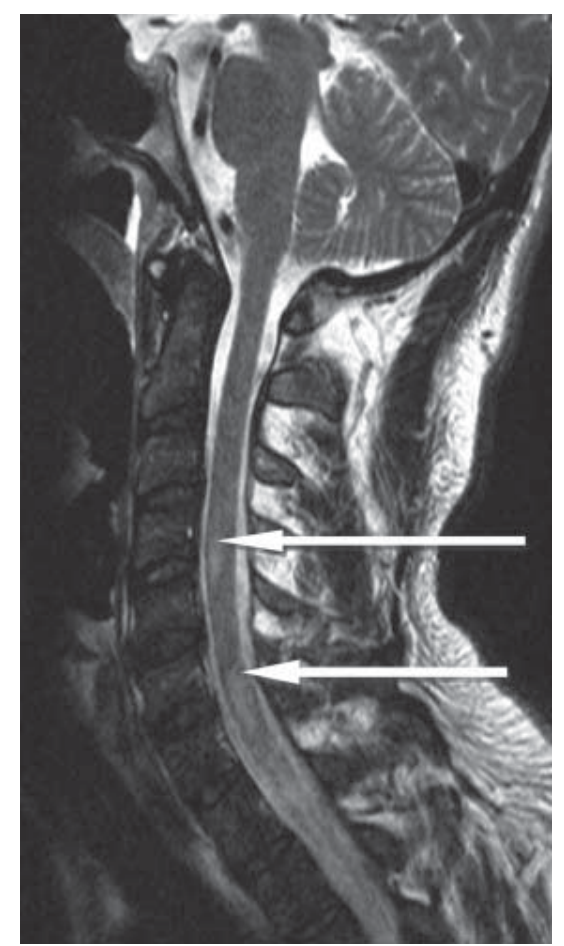

Figura 1. Secuencia T2 corte sagital de Resonancia Magnética de columna cervical que muestra imágenes hiperintensas en 2 segmentos extensos compatibles con lesiones inflamatorias. y test serológico para Mycoplasma pneumoniae. La resonancia magnética (RNM) cerebral fue normal y la RNM de médula evidenció lesiones inflamatorias, difusas, extensas en los segmentos cervical, y dorsal de la médula (ver Figuras).

Se inició metilprednisolona $1 \mathrm{~g}$ al día durante 3 días y ganciclovir iv $300 \mathrm{mg}$ al día. A las $48 \mathrm{~h} \mathrm{el}$ paciente recuperó la fuerza en extremidades por completo; la retención urinaria persistió por 1 mes para resolverse por completo en el segundo mes de seguimiento.

El control de LCR a los 10 días mostró una PCR negativa para virus de la familia Herpesviridae. Se observaron 15 células con proteinas en rango normal. La repetición de la PCR en la muestra inicial de LCR, tomada al ingreso, también fue negativa. El diagnóstico de alta fue mielitis viral asociada a HHV-7.

Los controles posteriores a los 6 meses de evolución evidenciaron un paciente sano, sin signos de haber desarrollado inmunodeficiencia.

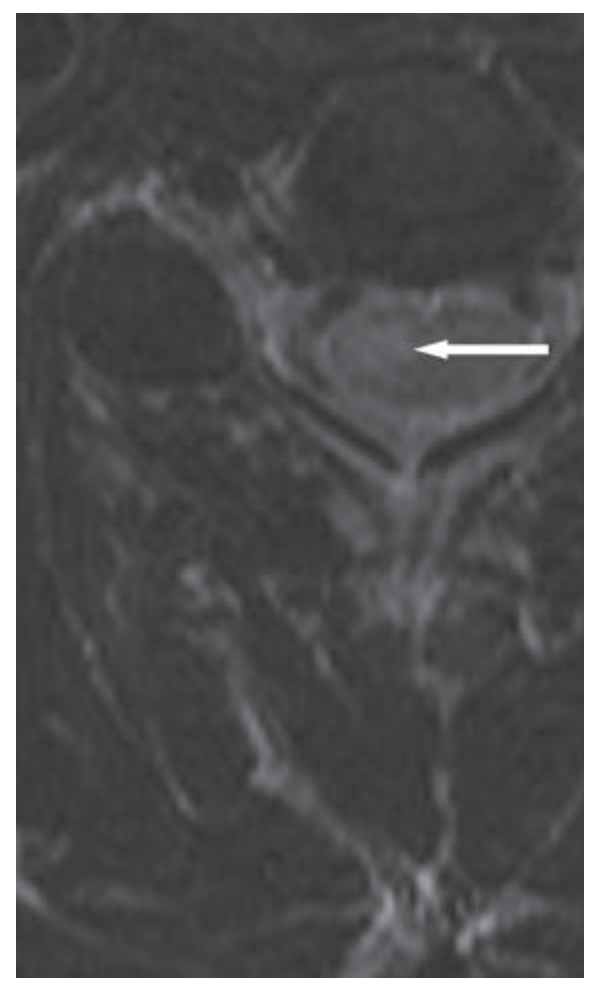

Figura 2. Secuencia Flair corte axial de Resonancia Magnética columna dorsal que muestra imagen hiperintensa en prácticamente una mitad de la medula espinal. 
Caso 2

Un hombre de 27 años, publicista, previamente sano, presentó cuadro de de 5 días de duración caracterizada por cefalea persistente, fiebre $\left(38,5^{\circ} \mathrm{C}\right)$, malestar general y diarrea. En el examen estaba alerta, sin anormalidades en el examen neurológico; en particular no se detectaron signos meníngeos. El hemograma, velocidad sedimentación, proteina $\mathrm{C}$ reactiva y otros cultivos fueron normales. El LCR mostró 160 células, predominio mononucleares y la proteína fue de $75 \mathrm{mg} / \mathrm{dl}$. La deteccion viral por PCR-Microarray (Entherpex ${ }^{\circledR}$, Genomica, España) identificó VHH-7 en LCR; el mismo test fue negativo en sangre y también negativo al repetirlo al cabo de 1 semana en la muestra inicial de LCR. HIV y HTLV-1 fueron negativos. El paciente fue manejado con analgésicos y reposo con muy buena evolución en 48 hrs, dándose de alta con diagnóstico de meningitis viral por HHV-7.

El control ambulatorio posterior hasta 6 meses no mostró ninguna complicación inmunitaria y un excelente estado de salud.

\section{Discusión}

Estos 2 casos sugieren la posibilidad que el VHH-7 pueda asociarse a patología neurológica en individuos inmunocompetentes, hecho escasamente reconocido en la literatura. La sintomatología puede variar en intensidad pudiendo afectar seriamente el SNC como lo demuestra el primer caso en K. N. Ward, infectóloga inglesa, quien comunicó el año 2002 un caso de infección por VHH-7 con parálisis fláccida en un adulto inmunocompetente, y posteriormente el año 2005 los primeros casos en población pediátrica que se manifestaron con convulsiones febriles y encefalitis ${ }^{2,3}$. Ginanneschi y cols. comunicaron el año 2007 también la infección concomitante de $\mathrm{VHH}-7$ con citomegalovirus en un paciente inmunocompetente que debutó con mielitis ${ }^{4}$.

Se estima que $90 \%$ de los adultos son seropositivos para HHV-7. La primoinfección ocurre en la edad pediátrica ( 2 a 3 años). Se transmite a través de la saliva y probablemente vía vertical; quedando en estado latente en el SNC, donde puede reactivarse posteriormente ${ }^{5}$, esto podría explicar la negatividad de la PCR en sangre en el primero de nuestros casos.
El Foro Internacional para manejo de infecciones herpéticas ${ }^{6}$ ha recomendado el uso de PCR para el adecuado diagnóstico dada su alta sensibilidad y especificidad, y no el cultivo viral en tejido o la detección de antigenos. Los resultados de la PCR-Microarray disponible en nuestro medio deben ser interpretados con cautela. Esta técnica permite la identificación de ARN viral y no de ADN genómico. En nuestros dos casos, la repetición de la PCR-Microarray días después, a partir de la muestra inicial de LCR, fue negativa. Esto se explica probablemente porque la muestra fue almacenada en condiciones no óptimas $\left(4^{\circ} \mathrm{C}\right)$ y en soluciones no adecuadas para la conservación de moléculas $A R N$, facilitando la rápida degradación del ARN, impidiendo su detección en el segundo ensayo. En estos casos, hubiese sido de utilidad detectar además el ADN de VHH-7, sin embargo, esta técnica no esta disponible en nuestro centro. En los 2 casos clínicos, la PCRMicroarray inicial en LCR fue positiva, con controles internos y controles negativos adecuados, sin existir evidencia de contaminación de la reacción.

Respecto al tratamiento de la infección por VHH-7, no existen trabajos que avalen una terapia antiviral, algunos centros mencionan el uso de ganciclovir por su actividad antiviral in vitro ${ }^{5}$, pero no está aceptado como recomendación.

Para el diagnóstico diferencial de primer caso presentado, podría plantearse una forma inicial de enfermedad desmielinizante. Sin embargo, las extensas lesiones inflamatorias no corresponden a lo observado en esclerosis múltiple (EM) son más focalizadas. Tampoco se detectaron otras lesiones en la RNM cerebral ni bandas oligoclonales, hecho frecuente en EM. El hallazgo de PCR para VHH-7 puede descartar y hace improbable que estemos frente a una primera manifestación de EM.

Una limitación de nuestra comunicación es no disponer de datos de seroconversión o de la detección de $\mathrm{ADN}$ genómico del virus, técnica no disponible en Chile, que confirmaran nuestros resultados. Sin embargo, la técnica empleada tiene alta sensibilidad y especificidad.

En suma, estos casos muestran que en nuestro medio $\mathrm{VHH}-7$ puede ser un patógeno a considerar aún en población inmunocompetente. La validación de técnicas moleculares altamente sensibles y específicas son fundamentales en nuestro medio. 


\section{Referencias}

1. Andersen O. Myelitis. C Curr Opin Neurol 2000; 13: 311-6.

2. Ward KN, Andrews NJ, Verity CM, Miller E, Ross EM. Human herpesvirus -6 and -7 each cause significant neurological morbidity in Britain and Ireland. Arch Dis Child 2005; 90: 619-23.

3. Ward KN, Kalima P, MacLeod KM, Riordan T. Neuroinvasion during delayed primary infection in an immuno- competent adult with encephalitic and flaccid paralysis. J Med Virol 2002; 67: 538-41.

4. Ginanneschi F,Donati D, Moschettini D, Dominici F, Cermelli C, Rossi A. Encephaloradiculomyelitis associated to HHV-7 and CMV co-infection in immunocompetent host. Clinical Neurology and Neurosurgery 2007; 109: 272-6.

5. www.hopkinsabxguide.org/pathogens/viruses/hhv_6_ hhv_7.html? contentInstanceId $=255974$

6. Boiving G. Diagnosis of herpes virus infections of the central nervous system. Herpes 2004; 11: 48A-56A. 